\title{
Grupos de convivência para idosos: participantes, egressos e desinteressados ${ }^{1}$
}

\section{Socialization groups for the elderly: participants, drop-outs, and uninterested}

\section{Grupos de convivencia para ancianos: participar, salir y desinteresarse}

\author{
Aline Oliveira Dias Moura* \\ Universidade Federal de Minas Gerais - UFMG, Belo Horizonte, Minas Gerais, Brasil \\ Luciana Karine de Souza** \\ Universidade Federal de Minas Gerais - UFMG, Belo Horizonte, Minas Gerais, Brasil
}

\begin{abstract}
RESUMO
Grupos de Convivência (GCs) para idosos são idealizados como locais de excelência na oferta de lazer ao idoso. Essa idealização pode limitar a busca por práticas de lazer mais condizentes com interesses e necessidades do envelhecente. Investigar os motivos da participação, da saída e do desinteresse por GCs é raro na literatura, mas socialmente relevante. Foram entrevistados 12 idosos participantes de GC, 12 egressos e 12 desinteressados sobre motivos da participação, saída, ou desinteresse por GCs. Além de motivos familiares e de saúde, foram evidentes as justificativas sobre relações com os profissionais e colegas e diferenças entre GCs, tanto quanto à programação, como à acessibilidade urbana ao local. Idosos desinteressados de GCs relataram grande ocupação do tempo livre com atividades prazerosas, de descanso e de desenvolvimento pessoal e social.
\end{abstract}

Palavras-chave: idoso, atividades de lazer, tempo livre.

\section{ABSTRACT}

Socialization groups (SGs) for the elderly are idealized places of excellence in leisure for the elderly. This idealization may limit the search for leisure practices more tuned to interests and needs of the aging individual. The literature seldom shows investigations on reasons for participation, giving up and nor being interested, yet this is a socially relevant topic. We interviewed 12 elders that attend a SG, 12 ex-participants, and 12 non-participants about their reasons for participating, leaving or not being interested in SGs. Besides family and health reasons, their motives included interpersonal relations with physical educators and colleagues and differences among SGs, the activities offered, and urban accessibility to get there. Elders not interested in SGs reported an extensive occupation of their free time with pleasurable activities, rest, and activities that promote personal and social development.

Keywords: elderly, leisure activities, free time.

\section{RESUMEN}

Los Grupos de Convivencia (GC) para adultos mayores son idealizados como excelentes lugares de oferta de actividades de ocio para ancianos. Esta 
idealización puede limitar la búsqueda por prácticas de ocio más acordes con sus intereses y necesidades. Investigar las razones para participar, salir o desinteresarse en los GC es inusual, pero socialmente relevante. Se entrevistaron 12 ancianos participantes de GC, 12 que abandonaron y 12 desinteresados en participar, sobre sus motivos para ello. Además de razones familiares y de salud, se evidenciaron justificaciones sobre relaciones interpersonales, así como diferencias entre GC respecto a la programación y a la accesibilidad urbana al local. Los ancianos desinteresados en GC citaron gran ocupación del tiempo libre con actividades placenteras, de descanso y de desarrollo personal y social.

Palabras clave: anciano, actividades recreativas, tiempo libre.

\section{Introdução}

Grupos de Convivência (GCs) consistem em oportunidades para a sociabilidade de pessoas mais de 60 anos de idade. São igualmente conhecidos por centros de vivência, clubes ou grupos da terceira idade/de idosos (Oliveira \& Cabral, 2004). Esses grupos facilitam relações interpessoais, monitoramento de direitos, desempenho de papéis sociais, estratégias para lidar com sofrimentos (físico, psicológico, social), desenvolvimento da criatividade, aprendizagem de novas habilidades (ou retomada de outras) e colaboram na adaptação saudável à velhice (Ferrari, 2002).

GCs são idealizados, socioculturalmente (Melo, 2003; Rezende, 2008), como locais quase exclusivos de excelência na oferta de lazer ao idoso. Essa idealização pode limitar a busca por práticas de lazer mais condizentes com interesses e necessidades do envelhecente.

Há uma escassez de estudos nacionais que investiguem, de forma aprofundada, os motivos que levam idosos a permanecerem por muito tempo em grupos de convivência, a não se interessarem em ingressar nesses grupos, e a participarem desses grupos temporariamente e optarem por sair. Por essas razões entende-se que investigar esses motivos (participação, saída e desinteresse) é socialmente relevante e cientificamente necessário.

\section{Motivos relacionados à busca de idosos por programas de lazer e à permanência por tempo prolongado}

Há uma boa quantidade de estudos que disponibilizam dados de entrevistas e questionários acerca dos fatores que levam idosos a participar de programas de lazer específicos à sua faixa etária, e/ou a permanecer nesses locais por bom tempo. Porém, há escassez de estudos que aprofundem as escolhas desses indivíduos, desconsiderando, por exemplo, uma possível relação de dependência dele com o programa.

A comunidade científica e os profissionais que atuam na prática reconhecem os ganhos dos idosos com esses programas. A literatura científica nacional disponível demonstra que os idosos: buscam projetos de extensão universitária por entendê-los como oportunidade de lazer 
(Gomes \& Pinto, 2006); frequentam universidades abertas para a terceira idade para adquirir conhecimento, amizades, novo sentido de vida, ocupar o tempo livre e ter lazer (Souza, 2001, 2004); participam de programas de lazer para aumentar a participação social e ampliar amizades (DeGáspari \& Schwartz, 2005; Fenalti \& Schwartz, 2003; Gomes \& Pinto, 2007; Oliveira \& Cabral, 2004; Pereira, Pereira, \& Morelli, 2006; Souza \& Garcia, 2008); procuram manter o equilíbrio biopsicossocial (Penna \& Santo, 2006), promover a saúde por indicação médica (Penna \& Santo, 2006), amenizar ou eliminar dores (Gomes \& Pinto, 2007), melhorar a saúde em geral (Fenalti \& Schwartz, 2003) e a qualidade de vida (DeGáspari \& Schwartz, 2005); querem ampliar a vontade de viver (Fenalti \& Schwartz, 2003; Gomes \& Pinto, 2007); livrarem-se da solidão e aumentar a autoestima (Bulsing, Oliveira, Rosa, Fonseca, \& Areosa, 2007).

Ainda com respeito aos efeitos da participação nesses grupos, Oliveira e Cabral (2004) buscaram compreender as relações sociais nas atividades de lazer nos GCs de camadas populares de Campina Grande (PB). Os idosos entrevistados relataram que os recessos do grupo são vistos negativamente e com alta expectativa pela volta ao programa, especialmente porque esses participantes praticamente só saem de casa para ir ao GC e se divertir.

\section{Motivos relacionados à saída dos idosos dos GCs ou à não participação nos grupos}

A desistência ou o desinteresse de idosos em programas de lazer ou de exercício físico específicos a essa faixa etária são pouco abordados na literatura científica nacional. São relatados problemas de saúde do idoso ou do cônjuge, morte do cônjuge ou de familiares, ou problemas no deslocamento até o local do GC (Cardoso, Borges, Mazo, Benedetti, \& Kuhnen, 2008; Gomes \& Pinto, 2007; Varoto, Truzzi, \& Pavarini, 2004). Ademais, outros empecilhos também desmotivam idosos a procurarem GCs, como a ausência de companhia para a realização da atividade, de recurso financeiro para custeá-la, de motivação para alterar a confortável rotina, a violência dos centros urbanos, bem como a ideia de que há experiências de lazer inadequadas para a idade avançada (Gomes \& Pinto, 2007).

Compreender as razões para desistência ou desinteresse que não estejam relacionadas à saúde física do idoso nem de seus familiares pode contribuir para o planejamento de programas e para a elaboração de outras possibilidades de oferta de lazer. Na visão de Pereira, Pereira e Morelli (2006), há um preconceito generalizado, tanto da sociedade com relação ao idoso, como do idoso em relação a si, denominando essa faixa etária como aquela destinada a limites físicos e culturais, restrita a pequenos (des)interesses específicos aos idosos, incapaz de buscar algo novo e diferente. Sobretudo deve-se confrontar a noção equivocada de homogeneização da velhice que também invade o campo dos estudos de 
lazer, a fim de que possam ser compreendidas as necessidades dos idosos dentro da relação de demanda e oferta de práticas de lazer.

Além da homogeneização da velhice, outro aspecto precisa ser combatido, esse mais atual: a glamourização da terceira idade (Melo, 2003; Rezende, 2008). Ela determina que todos os idosos são pessoas altamente engajadas, do ponto de vista social, e com elevado índice de tempo livre. Paradoxalmente essa glamourização tende a negar a velhice na sua especificidade e heterogeneidade. Alves Junior (2004) se alia aos demais autores ao afirmar como é temerário considerar a velhice como um período no qual o ser humano tem acesso a tudo, ignorando diferenças sociais, desigualdades e injustiças que grande parte dessa faixa etária da população brasileira experimenta.

Além disso, "em nível de senso comum pode parecer que, após a vida do trabalho, o idoso desfruta integralmente de um tempo que é livre e automaticamente ligado ao lazer, numa relação ao meu ver mecânica e reducionista" (Uvinha, 1999, p.158). Muitos idosos trabalham informalmente, possuem obrigações familiares, prestam serviços diversos, ou até acabam voltando ao mercado formal de trabalho (Melo, 2003).

A Comissão direcionada à Terceira Idade da World Leisure and Recreation Association (Associação Mundial de Lazer e Recreação) juntamente com pesquisadores e profissionais do campo do lazer desenvolveram um estudo para a construção de parâmetros de pesquisa e para a discussão sobre a questão do idoso e o lazer. McPherson (2000) faz um alerta ao perigo da homogeneização ao afirmar que "aqueles que se dedicam a fornecer serviços ou produtos de lazer precisam analisar as mudanças no tamanho, na composição e na distribuição da população idosa e de meiaidade" (p. 234).

Alguns idosos preferem locais onde há contato com outras gerações. Isso é destacado por Magnani (2009) ao discutir a pequena participação masculina nos GCs. Para o autor, "ao invés de serem confinados a lugares específicos, poder-se ia pensar em formas de ampliar seu direito de circular, de usufruir. (...) a cidade, na diversidade de seus espaços e equipamentos, abre um leque muito mais rico, mais amplo" (p.10). Alves Junior (2008) também argumenta na direção de se evitar "guetos de idosos".

Finalmente, cabe pensar que muitos idosos podem optar ocupar o tempo com atividades individualizadas (como um hobby, por exemplo) ou mesmo fazer nada. Segundo Melo (2003), dois aspectos precisam ser rompidos nesse sentido: o lazer como atenuante de problemas em relacionamentos interpessoais; e o tempo de lazer sempre ocupado e com atividades totalmente produtivas.

Nessa direção, Debert (1999) busca desconstruir o ideal do idoso ativo. O estereótipo da velhice solitária e abandonada tem sido trocado pela velhice ativa. Criou-se, com isso, um "super-idoso", pois ele é criativo diante de mudanças sociais, revisita sua identidade, obtém novas maneiras de se relacionar e usufruir de lazer. Essa celebração do envelhecimento, segundo Debert (1999), trata esta etapa da vida como portadora de privilégios para a realização pessoal e de eterna juventude, 
facilmente alcançada com novas formas de se vestir, de obter lazer e de se relacionar. Para a autora, o idoso que atrapalha esse ideal é o que não quer se diferenciar, não busca novidades, não busca lazer, não ingressa em GCs e nem faz exercícios.

Como argumentado em outra ocasião (Dias \& Souza, 2011), o lazer por vezes é utilizado como estratégia para negar o envelhecimento. Essa estratégia, no entanto, pode virar-se contra seu usuário, dado que muitos programas com essa visão podem afastar idosos que não se identificam com essa concepção de lazer nem de velhice superativa.

O presente estudo objetiva conhecer as razões que 1 ) levam idosos a permanecerem por longo tempo em um mesmo GC; 2) motivam o egresso de idosos de certo GC; e 3) condicionam a opção de idosos a não fazer parte desse tipo de grupo. Entende-se que é possível contribuir para futuros projetos de GCs para idosos, bem como para a muito escassa literatura sobre egressos e desinteressados nesses grupos.

\section{Procedimentos metodológicos}

\subsection{Amostra do estudo}

Compuseram a amostra deste estudo três perfis de idosos (idade mínima de 60 anos): 12 idosos que participam de um GC específico para sua faixa etária (participantes); 12 que já participaram de um GC por pelo menos seis meses e optaram por sair (egressos); e 12 que nunca participaram de um GC (desinteressados). Foram contatados os três GCs mais antigos ainda em funcionamento na cidade registrados na Prefeitura de Belo Horizonte (PBH) e que não cobram mensalidade. Buscou-se obter o mesmo número de homens e mulheres em cada grupo amostral (6 homens e 6 mulheres), sem distinção socioeconômica. Todos exibiram capacidade para participar de uma entrevista, demonstrando desempenho cognitivo adequado e ausência de problema de saúde ou patologia que pudesse interferir na interação com a pesquisadora.

Foram 12 os participantes de GCs que colaboraram com a pesquisa. Foi possível obter quatro entrevistas de cada um dos três GCs indicados pela $\mathrm{PBH}$. O segundo grupo amostral, de 12 egressos, foram contatados a partir dos GCs dos participantes, e também formado por quatro idosos por GC. Foram convidados aqueles que vivenciaram no mínimo a programação completa de um semestre do GC para que assim pudessem ter optado de maneira mais esclarecida a não regressar no semestre seguinte. Os desinteressados foram 12 indivíduos que nunca frequentaram GCs. Foram localizados pela indicação de participantes e/ou egressos dos GCs contatados e indicações de pessoas conhecidas, desde que atendessem aos critérios da pesquisa. Os desinteressados foram brevemente questionados por telefone sobre atividades de lazer externas ao lar. Afinal, grande parte dos estudos científicos disponíveis descreve atividades de lazer que idosos costumam praticar em casa (Doimo, Derntl, \& Lago, 2008; Gomes \& Pinto, 2006) e foi objetivo desta pesquisa buscar outros 
motivos possíveis para estas pessoas não frequentarem o GCs. Aqueles que realizam atividades de lazer fora do lar foram convidados a entrar no estudo.

A faixa etária dos 36 idosos variou de 60 a 90 anos, com média de 70,9 anos. Dos entrevistados, 14 homens são casados, dois são separados/divorciados, um é viúvo e um é solteiro. Das entrevistadas, 9 são viúvas, seis são casadas e três são solteiras.

\subsection{Instrumentos para a coleta de dados}

Três roteiros de perguntas foram desenvolvidos segundo o grupo amostral de idosos. As perguntas direcionadas aos participantes buscaram os motivos a permanecerem por tempo prolongado no GC; as perguntas aos egressos objetivaram detectar os motivos da saída do GC; e as perguntas para os desinteressados visaram as razões da ausência de interesse em participar de GCs. Foram solicitadas as informações de idade, sexo e estado civil. Um gravador de áudio foi utilizado para o registro das entrevistas, posteriormente convertido em arquivo, por participante, e transcrito.

\subsection{Procedimentos de coleta e análise dos dados}

A PBH assinou o Termo de Anuência Institucional, após o qual foram obtidos os dados de contato dos GCs. Os três GCs que aceitaram colaborar também assinaram um Termo de Anuência Institucional para o GC. O cadastro de participantes e egressos foi consultado para identificar participantes e egressos com idade mínima de 60 anos. Posteriormente, os idosos pré-selecionados como participantes ou egressos foram convidados e, após aceite, leram e assinaram o Termo de Consentimento Livre e Esclarecido (TCLE). Foi solicitado a eles a indicação de sujeitos que não se interessam em frequentar GC; outras indicações realizadas por contatos sociais da pesquisadora também foram acionadas. Após contatados e terem aceitado o convite, o grupo de desinteressados leram e assinaram o TCLE.

Foi assegurada ampla liberdade de participação na pesquisa sem prejuízos aos idosos. Eles foram informados dos objetivos, benefícios, riscos mínimos, garantias de privacidade, anonimato e sigilo. As entrevistas foram realizadas em local apropriado, com conforto e mínimo ruído exterior, sem acesso de outras pessoas no decorrer da entrevista. A maior parte dos egressos e todos os desinteressados preferiram ser entrevistados em casa (alguns, embora poucos, por telefone); os participantes foram entrevistados em sala do GC que frequentavam.

Os dados obtidos através das entrevistas foram analisados com inspiração nos passos do método de Análise de Conteúdo (Bardin, 2009): préanálise; exploração do material; tratamento dos resultados, inferência e interpretação. Na etapa de pré-análise os relatos foram escutados e transcritos a fim de gerar impressões iniciais sobre os dados acerca das informações obtidas. Os dados das entrevistas dos participantes e dos 
egressos foram organizados em frequência no GC, motivos para procurar o GC, motivos para permanência no GC, atendimento às expectativas de lazer, práticas de lazer externas ao lar, anseio por novas experiências de lazer, preferências de lazer. Os dados dos relatos dos desinteressados foram organizados em motivos pelo não interesse em GCs, motivos pelo interesse no lazer na instituição a qual se conecta atualmente, anseio por novas experiências de lazer, práticas de lazer externas ao lar, e preferências de lazer.

A exploração do material permitiu a identificação de diferenças, paridades e relações entre os relatos a fim de gerar categorias que reunissem unidades de sentido semelhantes. Cabe ressaltar que um mesmo idoso pode ter resposta em mais de uma categoria. Esta etapa contou com o envolvimento de duas avaliadoras e, em casos de discordância, consultavam uma terceira avaliadora. A última etapa de análise consistiu em selecionar os dados mais significativos para a pesquisa e na consulta à revisão da literatura para explicar os resultados.

\section{Resultados}

As respostas sobre os motivos para os participantes procurarem o GC foram agrupadas nas categorias seguintes:

- Preocupação com saúde ( 7 respostas): por exemplo, estava com depressão, problema de coluna, precisava de ginástica, estava "muito parado", estava "na idade" (de entrar no GC).

- Relacionamentos interpessoais (4): para conhecer pessoas, ter amigos.

- Cônjuge (4): ficou viúva e sozinha, para acompanhar a esposa.

- Sair de casa (3): para fazer algo fora de casa.

- Outros motivos (2): aposentou-se, mudou-se para perto do local do GC.

Seis participantes integram um GC de 8 a 10 anos. Dois indivíduos apresentaram imprecisão quanto ao tempo de frequência no GC, e os demais estão há mais de 10 anos.

Com respeito aos motivos da permanência no GC, 7 idosos relataram a preocupação com a saúde. Em seguida, 6 relataram o vínculo com pessoas próximas no grupo e 6 o vínculo com o orientador do grupo. Assim, percebe-se que os vínculos afetivos foram, na verdade, a maior motivação para permanecer no grupo.

Os egressos relataram as seguintes razões para procurarem um GC:

- Preocupação com saúde (7 respostas): estava sem fazer atividade, estava com depressão, a idade já estava chegando, por indicação da UBS, porque precisava de ajuda.

- Relacionamentos interpessoais (6): estava sozinha, pelo convite de amigo, convite da irmã, precisava entrosar mais, conhecer mais pessoas.

- Cônjuge (6): ficou viúva, para acompanhar a esposa.

- Outros motivos (4): procurou um lugar mais alegre, estava com vontade de fazer algo, porque o GC é muito bom, tem dom para fazer exercícios.

Como se pode notar, as razões dos egressos de procura pelo GC são praticamente as mesmas dos participantes, com pequenas diferenças nas 
frequências de respostas (face quantitativa dos dados) e nos conteúdos dos "outros motivos" (face qualitativa dos dados). A frequência dos egressos no GC variou de 6 meses a 8 anos, sendo que uma pessoa não soube informar visto que fez parte da primeira turma do GC (ou seja, desde sua fundação). A maioria dos egressos ficou no GC de 2 a 3 anos. A maior parte, na verdade, fez parte do GC por período inferior a 3 anos. Como são escassos os estudos sobre os motivos de saída dos GCs, os dados encontrados na presente pesquisa serão mostrados em detalhe na Tabela 1. Também foi objetivo investigar possíveis influências de outrem para sair do grupo. Entretanto, os egressos afirmaram ausência de qualquer influência para sair do GC, com exceção de um idoso, que foi influenciado pela esposa a trocar de grupo.

\begin{tabular}{|c|c|c|}
\hline Motivo & Exemplo de resposta & $f$ \\
\hline \multirow[t]{4}{*}{ Família } & Morte da irmã; da filha & 5 \\
\hline & Esposa não pode mais ir & \\
\hline & Mulher me incentivou a ir para outro grupo & \\
\hline & Tive que cuidar dos netos & \\
\hline \multirow{2}{*}{$\begin{array}{l}\text { Problema } \\
\text { saúde }\end{array}$} & Adoeci; desgaste e artrose no joelho & 4 \\
\hline & Depressão, e a médica não autorizou mais & \\
\hline \multirow[t]{5}{*}{$\begin{array}{l}\text { Diferenças entre } \\
\text { GCs }\end{array}$} & $\begin{array}{l}\text { Acabou o baile, a gente ficou mais triste, } \\
\text { afastou mais }\end{array}$ & 4 \\
\hline & $\begin{array}{l}\text { Tinha um rapaz muito bom que fazia ginástica } \\
\text { com a gente lá; ele saiu, eu desgostei }\end{array}$ & \\
\hline & Preferi participar mais próximo da minha casa & \\
\hline & $\begin{array}{l}\text { Preferi outro grupo por ser mais vezes na } \\
\text { semana e mais centralizado, tava pesado } \\
\text { participar de dois }\end{array}$ & \\
\hline & Preferi hidroginástica particular, água quente & \\
\hline \multirow[t]{2}{*}{ Outros motivos } & Não tem ninguém para me levar & 3 \\
\hline & Ônibus aqui não presta & \\
\hline
\end{tabular}

A maior parte dos egressos alegou questões familiares, seguidas de problemas de saúde. Mas no andamento da entrevista outros conteúdos vieram à tona. A categoria de respostas "diferenças entre GCs" não foi localizada nos estudos prévios que relatam saída de integrantes de GCs. Ela reflete, portanto, aspectos inexistentes no GC em questão e existentes em outro grupo, ou mesmo alterações ocorridas no próprio GC, o que gerou desagrado no integrante, levando à sua saída.

A Tabela 2 mostra os dados coletados para as razões dos desinteressados a nunca terem procurado um GC. Pelo ineditismo desses dados, julgou-se interessante incluir na tabela o sexo do participante que emitiu a resposta exemplificada. 
Tabela 2

Motivos de desinteressados para não procurarem GC para idosos

\begin{tabular}{|c|c|c|c|}
\hline Motivo & Exemplo de resposta & M & $\mathrm{F}$ \\
\hline \multirow[t]{2}{*}{ Tempo ocupado } & Tenho minha vida toda preenchida & - & 2 \\
\hline & $\begin{array}{l}\text { Tempo cheio com serviço da casa e } \\
\text { voluntariado }\end{array}$ & - & 1 \\
\hline \multirow[t]{2}{*}{$\begin{array}{l}\text { Avaliações } \\
\text { negativas do GC }\end{array}$} & $\begin{array}{l}\text { Esses grupos tomam o dinheiro dos } \\
\text { aposentados }\end{array}$ & - & 1 \\
\hline & Tenho resistência ao termo "idoso" & - & 1 \\
\hline \multirow{2}{*}{$\begin{array}{l}\text { Sem } \\
\text { fixo }\end{array}$} & Vai quando quer (festas, passeios) & 1 & - \\
\hline & $\begin{array}{l}\text { Quero liberdade, não estou mais naquela } \\
\text { época de ter compromisso com horário }\end{array}$ & 1 & - \\
\hline \multirow[t]{2}{*}{ Família } & Passeia e entrosa muito com a família & - & 1 \\
\hline & $\begin{array}{l}\text { Tô curtindo netos, ficando disponível para } \\
\text { familia }\end{array}$ & - & 1 \\
\hline \multirow[t]{2}{*}{$\begin{array}{l}\text { Intergeracionali } \\
\text { dade }\end{array}$} & $\begin{array}{l}\text { Prefere trocas de experiências com outras } \\
\text { idades }\end{array}$ & - & 1 \\
\hline & $\begin{array}{l}\text { Frequento coisas com jovens, vou a } \\
\text { barzinhos, saio pra dançar }\end{array}$ & - & 1 \\
\hline
\end{tabular}

Observou-se que 6 pessoas relataram ter o tempo ocupado com muitas tarefas e afazeres, o que impediria a procura por GCs. Em seguida, vem as avaliações negativas sobre o GC ou, inclusive, sobre as pessoas que buscam esses grupos. Nas "outras razões", embora poucas respostas nessa categoria, duas delas dizem respeito a características de personalidade e preferência pessoal quanto à ocupação do tempo.

\section{Discussão}

Como maiores motivos para entrar e permanecer em um GC foram encontrados a busca por relacionamentos interpessoais e a preocupação com a saúde, tanto citados por participantes como por egressos. Esse resultado converge com estudos presentes na literatura científica nacional (DeGáspari \& Schwartz, 2005; Fenalti \& Schwartz, 2003; Gomes \& Pinto, 2007; Oliveira \& Cabral, 2004; Pereira, Pereira, \& Morelli, 2006; Penna \& Santo, 2006; Souza, 2001, 2004; Souza \& Garcia, 2008). Esses resultados eram esperados, pois muitos estudos já foram realizados nessa direção.

Com respeito a estudos acerca dos motivos que conduzem idosos a se retirarem de GCs, a busca por literatura como ponto de partida para o presente estudo encontrou apenas uma pesquisa. Varoto, Truzzi e Pavarini (2004) entrevistaram coordenadores de programas para idosos a fim de detectar possíveis motivos para a saída dos indivíduos. Os coordenadores desconheciam os motivos da maioria dos 181 idosos egressos, exceto 
justificativas recebidas como a morte do próprio participante (42), doença (42) e motivos familiares (11). Os autores referem dificuldade em encontrar os egressos, conseguindo confirmar o motivo de doença de 22 , restando 20 egressos não localizados.

No presente trabalho, o motivo dos egressos com maior número de respostas foi situações familiares, convergindo com o estudo recém citado. Em seguida, com mesmo número de respostas foram relatados os motivos problemas de saúde (resultado esperado) e diferenças entre grupos. É quanto a essas diferenças entre grupos que se deve procurar indicadores tanto de problemas nos GCs como indicadores de novas possibilidades de trabalho.

As diferenças entre grupos abrangeram respostas sobre as alterações realizadas no GC que desagradaram o idoso, ou sobre a preferência do idoso por outro espaço - ambos motivos não abordados anteriormente pela literatura científica nacional. Cabe observar, inclusive, que dos 4 entrevistados que saíram por motivos de saúde, todos possuíam um segundo motivo para sair e, dos 5 egressos por situações familiares, 2 também relataram outro motivo de saída.

Uma questão metodológica que se faz evidente, portanto, é procurar detalhar, no diálogo com o egresso, suas razões para saída. No cotidiano do trabalho com grupos de idosos é muitas vezes clara a intenção de nunca desagradar o coordenador do grupo, professor ou orientador de atividades, ou mesmo de nunca o contrariar. Em especial essa é uma atitude bem presente dentre mulheres idosas, posto que em maioria criadas e educadas na base da passividade, do freio à manifestação da opinião própria e cerceamento de liberdade e autonomia para interagir com outrem fora do âmbito familiar.

É interessante observar que todos os egressos se declararam satisfeitos quanto ao que era oferecido no GC. Entretanto, a presença ou ausência de uma prática específica no grupo foi justamente o motivo para a saída de 4 idosos, o que pode sugerir a falta de coragem do idoso em expressar suas críticas e/ou suas ideias dentro do GC, como recém argumentado. O entrevistado E24, por exemplo, declarou ter artrose no joelho; entretanto, faz hidroginástica em outro lugar e, ademais, muitos idosos frequentes às atividades apresentam limitações desse tipo. Nesse sentido, talvez a diferença entre o GC e o lugar onde ele pratica a hidroginástica tenha sido motivo maior para a saída desse idoso. Ademais, a saúde física vai se impor às relações afetivas construídas no outro grupo.

Com relação aos problemas de saúde, é importante investigar quais problemas são esses. A entrevistada E16 realmente possui diferentes limitações de saúde, não tem condição física para usar o transporte público, assim como não tem alguém para conduzi-la até o GC, nem mesmo para continuar com as relações de amizade. A entrevistada E13 também declarou a dificuldade em usar o transporte público disponível para acesso ao GC. Mais uma vez é necessário rever os acessos seguros e dignos aos equipamentos de lazer, conforme destacado por Marcellino, Barbosa e Mariano (2008, p.148): 
O lazer e a segurança precisam ser tratados não como mero esforço de entretenimento que pode camuflar uma situação de violência. (...) A busca da convivência e da felicidade não precisa de justificativas. Quem sabe, assim, não serão necessárias mais grades nas nossas casas e nos nossos parques e jardins.

Tirado (2000) aponta que em Belo Horizonte a precariedade na infraestrutura, no transporte público e na segurança prejudicam o acesso dos idosos às opções de lazer e, inclusive, à possibilidade de ampliar essas opções. Alguns sujeitos da presente pesquisa mencionaram o quão benéfico seria se a PBH disponibilizasse transporte para conduzi-los até os grupos de convivência. Ainda que se trata de uma sugestão por demais específica, diante de tantas dificuldades que a administração municipal precisa sanar, a ideia subjacente está na melhoria do transporte público e na conscientização das pessoas quanto ao lugar (literal e metafórico) dos idosos na circulação dos espaços urbanos.

Não foi encontrado estudo que investigasse os motivos para idosos não se interessarem em participar de GCs. Na presente pesquisa, o maior motivo para não participarem de um GC foi tempo ocupado (metade das pessoas abordadas como desinteressadas).

Conforme discutido anteriormente, essa razão combate uma série de argumentos da literatura científica e do senso comum, e descaracteriza essa fase da vida como detentora de imenso e total tempo livre, disponível para o indivíduo desfrutar o lazer que queira. A fala da entrevistada E35 ilustra essa mudança de paradigma: "Eu trabalhei 25 anos dando aula, e descobri que quando a gente aposenta a gente trabalha mais que quando a gente trabalha". Assim, uma desconstrução ou destruição da ideia de que o idoso dispõe de muito tempo livre deve ser empreendida.

O segundo motivo envolve percepções negativas de 4 entrevistados acerca do universo do GC, assim como dos que participam desses grupos. Os seguintes trechos de entrevistas são significativos em torno da imagem passada a alguns sobre seus integrantes: "E as pessoas que vão pro grupo de convivência, elas têm dificuldade de relacionamento, às vezes falta companhia, às vezes também o poder aquisitivo (...)" (E33, mulher), e "Eu acho que as pessoas se juntam nesses grupos por carência" (E29, homem). Nessas manifestações encontram-se, ao mesmo tempo, duas realidades. A primeira é de que pode ser difícil para o idoso estabelecer novos relacionamentos interpessoais, especialmente após a aposentadoria e/ou o falecimento do cônjuge. Fazer amigos não depende somente de características de personalidade, mas também de habilidades sociais que, muitas vezes, passam anos em desuso. Ademais, todos os envolvidos nessa categoria de respostas residem sozinhos e buscam principalmente, nas atividades que realizam e nos espaços que frequentam, interações sociais. A segunda realidade está no próprio preconceito que o idoso aplica sobre si. Afinal, parece que procurar grupos para idosos é admitir que se é um idoso, e isso nem sempre é algo fácil de reconhecer. Muitas pessoas acima dos 60 anos lutam deliberadamente contra a ideia de ser 
um idoso, não tanto pelo que o termo carrega, mas pela dificuldade em reconhecer o ingresso em uma nova etapa da vida.

\section{Considerações finais}

O objetivo da presente pesquisa foi conhecer os motivos de idosos para a participação e permanência em GCs, para a saída desses GCs, e para a ausência de interesse em neles ingressar. As motivações foram acessadas através de entrevistas individuais semiestruturadas a três grupos amostrais: participantes (de GCs), egressos e desinteressados.

Os resultados para os motivos de ingresso e de permanência não diferiram dos disponíveis na literatura. As razões de saída dos egressos, no entanto, revelaram uma classe de respostas denominada diferenças entre grupos, que ainda assim acompanhava manifestações de satisfação com relação ao grupo frequentado. Esse motivo indica duas observações: a primeira, da dificuldade do idoso em realizar suas críticas no espaço onde se insere, talvez por receio da perda dos vínculos afetivos adquiridos (imprescindíveis para sua permanência no grupo); a segunda, da tomada de decisão por parte do indivíduo em reconhecer falhas no grupo, ultrapassando a ideia de excelência e exclusividade desses grupos como possibilitadores de lazer para essa faixa etária, e por sua vez, em buscar conhecer e experimentar novas opções, novas possibilidades. Essa atitude de se permitir novas oportunidades poderia servir de exemplo para muitos idosos, tanto para aqueles que se encontram insatisfeitos e preferem não se manifestar, para que possam se encorajar e seguir em novas direções, como para aqueles que se sentem plenos, pela importância de verificar a existência de outras práticas de lazer, de outras formas de pensa-lo e vivencia-lo e assim, efetuar escolhas.

Outro dado merecedor de destaque é o fato de idosos desinteressados em GCs realizarem avaliações negativas acerca destes e daqueles que os frequentam. Esse achado sugere uma dificuldade desses indivíduos em lidar com a própria velhice, já que estão fundamentando sua opinião em preconceitos e estereótipos sobre a velhice - ou seja, aceitando estes argumentos negativos como verdades sobre esta fase da vida. Afinal, esses desinteressados, mesmo não frequentando um GC, buscam, em sua maioria, nos espaços onde se inserem e nas práticas de lazer evidenciadas, encontrar e/ou manter relações sociais. Esse resultado revela a necessidade dos seres humanos em estabelecer redes de ligações sociais, uma vez que é uniforme, nos três grupos amostrais, a busca pelo convívio em grupo. Mais uma vez é ressaltada a essencialidade das relações humanas para todo e qualquer sujeito, abordada por autores como Rezende (2008), e por Doimo, Derntl e Lago (2008).

Espera-se que esta pesquisa possa contribuir para a realização de futuros estudos científicos sobre lazer para idosos e sobre os GCs, bem como possa auxiliar profissionais e instituições que agregam GCs a melhor planejarem as atividades ofertadas, incluindo o idoso nas escolhas, a fim de que observem, registrem e entendam melhor as entradas, 
permanências prolongadas e saídas das pessoas. E ainda, almeja-se que tanto os profissionais envolvidos quanto as instituições reflitam sobre a necessidade de fornecer meios de preparar os participantes a encararem com naturalidade possíveis mudanças no quadro de professores, por exemplo, a ampliarem suas experiências de lazer e relações interpessoais para além dos muros dos locais de encontro dos grupos, a avaliarem com criticidade sua participação no grupo.

Nesse sentido, é também intuito do presente estudo incentivar aqueles que exercem o papel de orientadores, em conjunto com a instituição onde o grupo se insere, a possibilitarem formas mais diferenciadas de lazer em grupo para essa faixa etária, reconhecendo falhas, recorrendo a sugestões e anseios dos idosos, usufruindo amplamente do ambiente e estrutura física (nos casos onde há essa possibilidade). É necessário estimular os profissionais envolvidos na oferta de lazer a idosos a realizarem avaliações dos espaços, das práticas de lazer, com envolvimento direto dos sujeitos, para que as responsabilidades do poder público possam ser cobradas, para que a ação profissional possa ser repensada, com o intuito de contribuir para a melhoria do usufruto do lazer por parte desses indivíduos.

Espera-se que as futuras pesquisas possam se empenhar em investigar diferentes perfis de idosos na relação com o lazer, como, por exemplo, estudar as diferenças de lazer entre idosos com distintas formas de moradia (residência própria, casa de familiares, ILPI), entre idosos oriundos de classes socioeconômicas diferentes entre si, entre idosos saudáveis e doentes. Enfim, há ainda uma gama de sujeitos a serem entrevistados, além dos envolvidos pelos GCs.

Enfim, cabe a todos aqueles que se destinam à interface lazer e velhice, seja na teoria e/ou na prática, recordar-se que o idoso, anteriormente à idade adquirida, é um ser humano como outro qualquer, com seus anseios, desejos, vontades de experimentar novas possibilidades. Dessa forma, é um indivíduo que merece ser ouvido, pelos mais diversos profissionais; ser incentivado e desafiado, condições que ampliam o significado da existência; ser atendido, por possuir direitos, como o direito ao lazer, necessário a qualquer pessoa.

\section{Referências}

Alves Junior, E. (2004). Procurando superar a modelização de um modo de envelhecer. Movimento, 10(2), 57-71.

Alves Junior, E. (2008). Lazer, idosos e aposentados: O Projeto Prevquedas. In E. Alves Junior, V. Melo, \& A. Brêtas (Orgs.). Lazer \& cidade: Reflexões sobre o Rio de Janeiro (pp. 49-217). Rio de Janeiro: Shape.

Bardin, L. (2009). Análise de conteúdo (ed. rev. e ampliada). Lisboa: Edições 70.

Bulsing, F., Oliveira, K., Rosa, L., Fonseca, L., \& Areosa, S. (2007). A influência dos grupos de convivência sobre a auto-estima das 
mulheres idosas do município de Santa Cruz do Sul-RS. Revista Brasileira de Ciências do Envelhecimento Humano, 4(1), 11-17.

Cardoso, A., Borges, L., Mazo, G., Benedetti, T., \& Kuhnen, A. (2008). Fatores influentes na desistência de idosos em um programa de exercício físico. Movimento, 14(1), 225-239b.

Debert, G. (1999). A reinvenção da velhice: Socialização e processos de reprivatização do envelhecimento. São Paulo: EdUSP/FAPESP.

DeGáspari, J., \& Schwartz, G. (2005). O idoso e a ressignificação emocional do lazer. Psicologia: Teoria e Pesquisa, 21(1), 69-76.

Dias, A. O., \&, Souza, L. K. De (2011). Entre textos e contextos: Relações sociais, motivação e lazer na velhice. Licere, 14(4), 1-42.

Doimo, L., Derntl, A., \& Lago, O. (2008). O uso do tempo no cotidiano de mulheres idosas: um método indicador do estilo de vida de grupos populacionais. Ciência e Saúde Coletiva, 13(4), 1133-1142.

Fenalti, R., \& Schwartz, G. (2003). Universidade aberta à terceira idade e a perspectiva de ressignificação do lazer. Revista Paulista de Educação Física, 17(2), 131-141.

Ferrari, M. A. C. (2002). Lazer e ocupação do tempo livre na terceira idade. In M. P. Netto (Org.), Gerontologia: a velhice e o envelhecimento em visão globalizada (pp. 98-105). São Paulo: Atheneu.

Gomes, C., \& Pinto, G. (2006). O lazer na velhice: Reflexão sobre as experiências de um grupo de idosos. Kairós, 9(2), 113-133.

Gomes, C., \& Pinto, G. (2007). Pesquisando o lazer de um grupo de idosos no Brasil. LÉCTURAS: Revista Digital (Buenos Aires), 11(106). Retirado de http://www. efdeportes.com/

Magnani, J. (2009). O homem idoso e sua participação social: Lazer, militância política e cultural. In Anais eletrônicos do Seminário Envelhecimento Masculino. São Paulo: SESC.

Marcellino, N., Barbosa, F., \& Mariano, S. (2008). Espaços e equipamentos de lazer: Apontamentos para uma Política Pública. In N. Marcellino (Org.). Políticas públicas de lazer (pp. 133-152). Campinas: Alínea.

McPherson, B. (2000). Envelhecimento populacional e lazer. In SESC/WRLA, Lazer numa sociedade globalizada (pp. 227-249). São Paulo: SESC.

Melo, V. (2003). Programas de lazer para idosos no Brasil: Sugestões com base em um panorama. In V. Melo (Org.), Lazer e minorias sociais (pp. 57-71). São Paulo: Ibrasa.

Oliveira, M., \& Cabral, B. (2004). O lazer nos grupos de convivência para idosos: prática renovada de sociabilidade. In Anais do 70 Encontro Latino-Americano de Iniciação Científica \& 4으 Encontro LatinoAmericano de Pós-Graduação (pp. 1632-1638). São José dos Campos: Universidade do Vale do Paraíba.

Penna, F., \& Santo, F. (2006). O movimento das emoções na vida dos idosos: um estudo com um grupo da terceira idade. Revista Eletrônica de Enfermagem, 8(1), 17-24. 
Pereira, L., Pereira, A., \& Morelli, G. (2006). A importância do lazer da terceira idade: Um estudo de caso em Ribeirão Preto. LÉCTURAS: Revista Digital (Buenos Aires), 98.

Rezende, R. (2008). Afeto, velhice e lazer. Licere (Belo Horizonte), 11(3), 1-21.

Souza, L. K. (2001). Uma nova chance: O idoso na universidade. In O. P. de Castro (Org.), Envelhecer: Um encontro inesperado? Realidades e perspectivas na trajetória do envelhecente (pp. 93-120). Sapucaia do Sul: Notadez.

Souza, L. K. (2004). Velho amigo, amigo velho: Amizade na velhice. In O. P. de Castro (Org.), Envelhecer: Revisitando o corpo (pp. 69-86). Sapucaia do Sul: Notadez.

Souza, L. K., \& Garcia, A. (2008). Amizade em idosos: Um panorama da produção científica recente em periódicos estrangeiros. Estudos Interdisciplinares Sobre o Envelhecimento, 13(2), 173-190.

Tirado, M. G. A. (2000). A percepção dos idosos sobre envelhecimento e independência: um estudo qualitativo no município de Belo Horizonte. Tese de Doutorado não-publicada. Universidade Federal de Minas Gerais, Belo Horizonte, MG, Brasil.

Uvinha, R. (1999). Lazer e qualidade de vida: Um enfoque na faculdade da terceira idade-FEFISA. Licere, Belo Horizonte, 2(1), 153-163.

Varoto, V., Truzzi, O., \& Pavarini, S. (2004). Programas para idosos independentes: Um estudo sobre seus egressos e a prevalência de doenças crônicas. Texto Contexto Enfermagem (Florianópolis), 13(1), 107-114.

\section{Endereço para correspondência \\ Aline Oliveira Dias Moura \\ Universidade Federal de Minas Gerais \\ Escola de Educação Física, Fisioterapia e Terapia Ocupacional, Programa de Pós- Graduação Interdisciplinar em Estudos do Lazer \\ Av. Presidente Antônio Carlos, 6627, Campus Pampulha, CEP 31270-901, Belo Horizonte - MG, Brasil \\ Endereço eletrônico: alineo.dias@hotmail.com}

\section{Luciana Karine de Souza}

Universidade Federal de Minas Gerais

Escola de Educação Física, Fisioterapia e Terapia Ocupacional, Programa de PósGraduação Interdisciplinar em Estudos do Lazer

Av. Presidente Antônio Carlos, 6627, Campus Pampulha, CEP 31270-901, Belo Horizonte - MG, Brasil

Endereço eletrônico: lukarides@gmail.com

Recebido em: 13/04/2015

Reformulado em: 11/08/2015

Aceito para publicação em: 20/08/2015

\section{Notas}

1 Este trabalho apresenta o primeiro conjunto inédito de dados da Dissertação de Mestrado defendida pela primeira autora, sob orientação da segunda, no Programa de Pós-Graduação em Estudos do Lazer da Universidade Federal de Minas Gerais (UFMG). Apoio: CAPES; PPG-Lazer/UFMG. Agradecimentos: D. C. Silveira, G. A. de Moura, G. M. 
Schwartz, L. F. M.-Diniz, J. Doll e M. G. A. Tirado. Esta pesquisa foi aprovada pelo Comitê de Ética em Pesquisa da UFMG no parecer ETIC190-11.

* Educadora Física, Mestre em Estudos do Lazer pela Universidade Federal de Minas Gerais.

** Psicóloga, Doutora em Psicologia pela Universidade Federal do Rio Grande do Sul. 